\title{
Antibacterial Properties of Silver-Loaded Plasma Polymer Coatings
}

\author{
Lydie Ploux, ${ }^{1}$ Mihaela Mateescu, ${ }^{1}$ Karine Anselme, ${ }^{1}$ and Krasimir Vasilev ${ }^{2}$ \\ ${ }^{1}$ Institut de Science des Matériaux de Mulhouse, CNRS LRC 7228, 15 rue Jean Starcky, BP2488, 68057 Mulhouse Cedex, France \\ ${ }^{2}$ Mawson Institute and School of Advanced Manufacturing, University of South Australia, Mawson Lakes Campus, \\ Mawson Lakes, SA 5099, Australia
}

Correspondence should be addressed to Lydie Ploux, lydie.ploux@uha.fr

Received 8 February 2012; Accepted 22 March 2012

Academic Editor: Haifeng Chen

Copyright (C) 2012 Lydie Ploux et al. This is an open access article distributed under the Creative Commons Attribution License, which permits unrestricted use, distribution, and reproduction in any medium, provided the original work is properly cited.

\begin{abstract}
In a previous paper, we proposed new silver nanoparticles (SNPs) based antibacterial coatings able to protect eukaryotic cells from SNPs related toxic effects, while preserving antibacterial efficiency. A SNPs containing n-heptylamine (HA) polymer matrix was deposited by plasma polymerization and coated by a second HA layer. In this paper, we elucidate the antibacterial action of these new coatings. We demonstrated that SNPs-loaded material can be covered by thin HA polymer layer without losing the antibacterial activity to planktonic bacteria living in the near surroundings of the material. SNPs-containing materials also revealed antibacterial effect on adhered bacteria. Adhered bacteria number was significantly reduced compared to pure HA plasma polymer and the physiology of the bacteria was affected. The number of adhered bacteria directly decreased with thickness of the second HA layer. Surprisingly, the quantity of cultivable bacteria harvested by transfer to nutritive agar decreased not only with the presence of SNPs, but also in relation to the covering HA layer thickness, that is, oppositely to the increase in adhered bacteria number. Two hypotheses are proposed for this surprising result (stronger attachment or weaker vitality), which raises the question of the diverse potential ways of action of SNPs entrapped in a polymer matrix.
\end{abstract}

\section{Introduction}

Biofilms are a common cause for biomaterials-related infections $[1,2]$, often leading to implant failure and removal [35]. Extensive research efforts in the fields of microbiology, chemistry, and material science have focussed on understanding bacteria-material surface interactions [6] and developing novel materials which are able to resist and fight against bacterial adhesion and biofilm formation [7]. The release of antibacterial agent from coatings or materials is one of the most promising solutions and many original socalled drug delivery systems have been reported in the literature [8-11]. This strategy has advantages to surface-immobilized antibacterial agents, because it acts on both adhered bacteria and planktonic bacteria living in the near surroundings. However, health risks related to the release of bioactive drug in the patient body remain an important cause of anxiety for both medical and general public.

Amongst many antibacterial agents, silver is probably the most famous. It has been known since the ancient times for its antibacterial properties and silver-based compounds have been used extensively in many applications $[12,13]$. After being neglected in the second 20th century part, the increased occurrence of antibiotics-resistant bacteria in infections has made silver popular again, especially for creating new antibacterial coatings and materials $[5,14-18]$. In its ionic form $\left(\mathrm{Ag}^{+}\right)$, silver is known to exhibit a strong toxicity to a wide range of microorganisms while the risk of bacterial resistance to silver is usually considered to be lower than to antibiotics. $\mathrm{Ag}^{+}$ions disturb biological functions such as permeability and respiration by interacting with the bacterial membrane. In addition, $\mathrm{Ag}^{+}$ions can penetrate inside the cell where they cause damage by binding with enzymes and DNA $[13,19,20]$. Silver nanoparticles (SNPs) also exhibit antibacterial properties via bacterial inactivation and growth inhibition $[21,22]$ but the mechanism of action is not yet completely understood [23].

Toxicity of silver ions to human cells is low and relatively high levels ( $2.89 \mathrm{~g}$ on silver-coated megaprostheses) have been used in patients without leading to any argyrosis and 
toxic side effects [24]. In addition, when embedded in a coating like a polymer matrix, SNPs cannot be released in the material surroundings. Rather, antibacterial properties are due to the release of silver ions resulting from the oxidation of embedded SNPs $[25,26]$. However, the potential toxicity of biomaterials containing silver in any form and in particular when used as nanoparticles remains a current question [27]. Therefore, protecting eukaryotic cells from direct contact with SNPs, even immobilized in coating, is a relevant challenge.

Recently, we demonstrated that it is possible to preserve antibacterial efficiency (Staphylococcus epidermidis) of a coating embedding SNPs, while protecting eukaryotic cells (SaOS2 osteoblastic cells) from the toxic effects due to direct contact with the embedded SNPs, [28]. This new coating was based on one matrix of n-heptylamine (HA) polymer, deposited by plasma polymerization, embedding SNPs. A second HA layer, covering the SNPs-containing matrix, protected eukaryotic cells from direct contact with the nanoparticles embedded in the matrix surface. In the present study, we aim to fully unravel the antibacterial action of these coatings. We focus on diverse aspects of antibacterial properties by considering effects on planktonic, that is, free living bacteria, adhered bacteria, and physiological state of planktonic and adhered bacteria. Three different thicknesses ( $6 \mathrm{~nm}, 12 \mathrm{~nm}$, and $18 \mathrm{~nm}$ ) of covering HA layer were considered, aiming at better understanding the role of the second layer in the preservation or the degradation of antibacterial properties.

\section{Materials and Methods}

2.1. Material Preparation. Material design (Figure 1(b)) and processing were described elsewhere [28]. Briefly, a $100 \mathrm{~nm}$ thick n-heptylamine (HA) plasma polymer film was deposited on clean glass slide of around $1 \mathrm{~cm} \times 1 \mathrm{~cm}$. The film was loaded with silver ions by immersion in $\mathrm{AgNO}_{3}$, which were subsequently reduced to silver nanoparticles by immersion in $\mathrm{NaBH}_{4}$. A second HA plasma polymer film was deposited on top of the SNPs-loaded film. In the present work, three different thicknesses of the second layer of $6 \mathrm{~nm}, 12 \mathrm{~nm}$, and $18 \mathrm{~nm}$ were considered. Two additional materials were used as a negative (HA film without loaded SNPs) and a positive control (SNPs loaded HA film without second layer). The samples used in the present work thus presented five types of architecture that are called as the following in the present paper: "Negative Control": Clean glass slide + 100 nm HA; "Positive Control": Clean glass slide + HA + SNPs; "6 nm": Clean glass slide + HA + SNPs + 6 nm HA; "12 nm": Clean glass slide + HA + SNPs + 12 nm HA; "18 nm": Clean glass slide + HA + SNPs + $18 \mathrm{~nm} \mathrm{HA}$. Negative Control was regarded as the reference surface for evaluating the SNPsrelated antibacterial efficiencies. Before use for microbiological investigation, samples were sterilized by UV $(254 \mathrm{~nm}$ wave length) during 7 minutes at $2 \mathrm{~cm}$ from the lamp. Characterisation and details of the different types of material were reported elsewhere [28]. The release kinetics of silver ions from the films was shown to be a function of the thickness of the second HA layer (Figure 1(a)).
2.2. Bacterial Culture. Microbiological investigation was conducted with Escherichia coli (E. coli) that are among bacteria the most frequently implicated in infections on implants. E. coli MG1655 (PHL628 [29]) known to produce curli and exocellular polymeric substances (EPSs) and to attach to abiotic surfaces was used. Bacteria were cultivated in a selective medium at $30^{\circ} \mathrm{C}$. Prior to each experiment, bacteria stored at $-80^{\circ} \mathrm{C}$ were spread on a Luria-Bertani (LB) nutritive medium agar plate and grown about 24 hours. Selective nutritive medium (M63G, pH 6.8 [29]) was then inoculated with one bacterial colony and let overnight at $30^{\circ} \mathrm{C}$. This culture was used to inoculate a second preculture $(10 \%$ vol. of first preculture) which was grown for about $4 \mathrm{~h}$ before inoculating the culture (10\% vol. of second preculture) finally used for experiments (containing about $5 \times 10^{6}$ bacteria/mL corresponding to an absorbance at $600 \mathrm{~nm}$ of 0.01 , measured by UV spectrophotometry $\left.\left(\mathrm{Abs}_{600 \mathrm{~nm}}\right)\right)$.

\subsection{Antibacterial Efficiency Analyses}

2.3.1. Antibacterial Efficiency in the Material Surroundings: Supernatant Analysis. This test aims at evaluating the capacity of the entrapped SNPs to inhibit bacterial growth in the surrounding aqueous medium. Each sterilized material sample was placed in a Petri dish with the polymer face up. $3 \mathrm{~mL}$ of bacteria suspension prepared as described above were inoculated and cultured at $30^{\circ} \mathrm{C}$ in contact with the sample. After 2 hours of culture, $2.5 \mathrm{~mL}$ of supernatant were harvested from the dish and replaced by $2.5 \mathrm{~mL}$ of $\mathrm{NaCl}$ solution $(9 \mathrm{~g} / \mathrm{L}$ in water). This process was repeated 3 times, leading to the following harvested solutions Initial supernatant, 1 st rinsing, 2 nd rinsing, $3 \mathrm{rd}$ rinsing, 4 th rinsing. The sufficient efficiency of 4 rinsing steps for harvesting all free living, that is, nonattached bacteria, was stated by a preliminary experiment (data not shown). Care has been taken that the samples remained in immersion for avoiding any supplementary cleaning through dewetting phenomena. Bacteria content of each harvested solution was assessed by absorbance measurement at $600 \mathrm{~nm}$ with a UV-spectrophotometer $\left(\mathrm{Abs}_{600 \mathrm{~nm}}\right)$. Abs $600 \mathrm{~nm}$ values were transformed in planktonic bacteria amount by using an "Abs $600 \mathrm{~nm}$ " versus "planktonic bacteria amount" calibration curve that was previously established by measuring the $\mathrm{Abs}_{600 \mathrm{~nm}}$ values of several dilutions of bacterial suspensions (data not shown). Planktonic bacteria amounts of initial supernatant and rinsing solutions were summed for each sample type in order to assess planktonic bacteria growth. Experiment for characterising antibacterial effect in supernatant was run 5 times.

\subsubsection{Antibacterial Efficiency in the Material Surroundings: "Diffusion" Test. This test aims at evaluating the capacity of the entrapped SNPs to inhibit bacterial growth in the close surroundings of the substrate. $100 \mu \mathrm{L}$ of a fresh bacterial suspension was spread on an LB agar plate in order to form a thin bacterial film. Sterilized material sample was placed in contact with this previously homogenously inoculated agar plate (sample top side in contact with agar). After overnight incubation at $30^{\circ} \mathrm{C}$, the inhibition area that potentially}




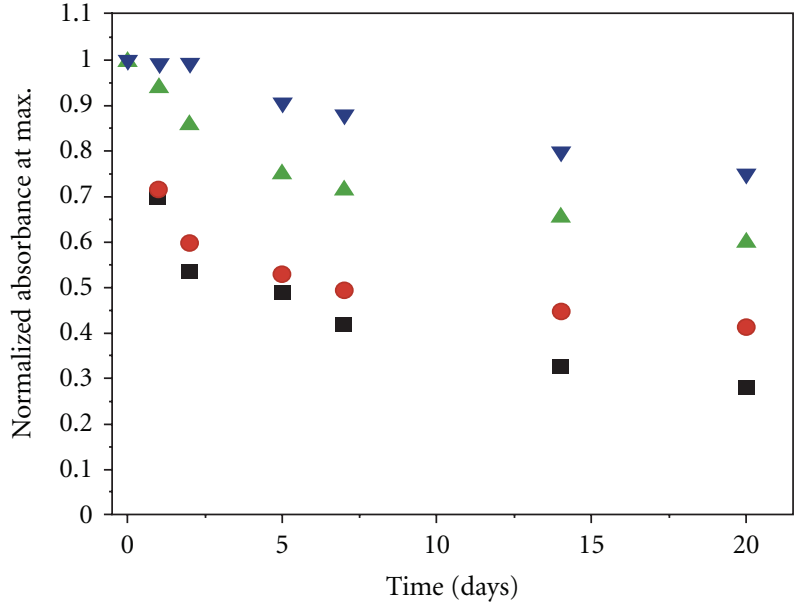

(a)

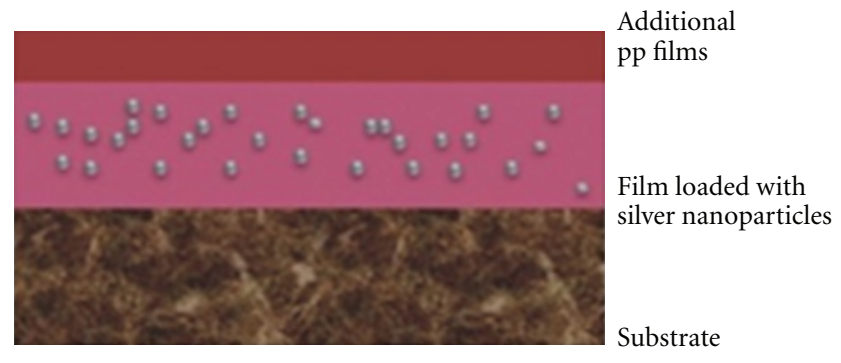

(b)

FIGURE 1: Control over the release of silver ions. Control over release of silver was achieved by depositing an additional layer of HA pp film on top of the silver nanoparticles loaded films (b). The graph on the left shows the kinetic of release of silver ions from the films over 20 -day immersion in PBS. Black squares—silver-loaded films as prepared; red circles—after deposition of $6 \mathrm{~nm}$ film of HA; green triangles-after deposition of $12 \mathrm{~nm}$ film of HA; blue triangles_-after deposition of $18 \mathrm{~nm}$ film of HA (reprinted with permission from [28], Copyright 2010 American Chemical Society).

appeared around the sample was measured. The inhibition area border was approximated by both a round and a square zone (Figure $2(\mathrm{a})$ ). Final value was obtained by averaging results of round zone and square zone approximations and subsequent subtraction of the sample area. "Diffusion" test experiment was run 3 times.

\subsubsection{Antibacterial Efficiency at the Material Surface: Direct} Observation under Fluorescence Confocal Microscope. This test aims at evaluating the capacity of the entrapped SNPs to inhibit the short-time colonisation of the material surface by bacteria. Each sterilized material sample was placed in a Petri dish with the polymer face up and treated as already describes above (Section 2.3.1). Finally, the last 4th rinsing solution was replaced by $2 \mathrm{~mL}$ of fresh $\mathrm{NaCl}$ solution without creation of any air-material interface. Bacteria attached on the material sample were observed to be immersed in the $\mathrm{NaCl}$ solution for keeping bacteria in physiological conditions. The upright Confocal Laser Scanning Microscopy (CLSM) (Carl Zeiss, LSM700) used for the observation was equipped with a long working distance objective (LD EC Epiplan Neofluar 50x/0.55 DIC M27). All CLSM observations were done in reflection mode, without any bacteria staining. Quantity of adherent bacteria was measured using Image J software [30]. Experiment for characterising antibacterial effect at the material surface was run 2 times.

\subsubsection{Antibacterial Efficiency at the Material Surface: "Print"} Test. This test aims at evaluating the proliferation capacity of bacteria adhered at the surface of the material samples. Each sterilized material sample was placed in a Petri dish with the polymer face up and treated as already described above (Section 2.3.1). After complete rinsing, the sample was taken out and its topside was slightly pressed for $5 \mathrm{sec}$ on LB agar plate. Sample was then taken off and the Petri dish was incubated for $16 \mathrm{~h}$ at $30^{\circ} \mathrm{C}$. The efficiency of bacteria transfer from material sample onto the LB-agar plate was supposed not to vary from a type of material to another. The proliferation capacity of bacteria initially adhered on the material was estimated as the capacity of the transferred bacteria to form colonies on the LB agar plates, which was assessed by measuring rate of sample surface covered by bacteria colonies. Measurement was performed by using image analysis with ImageJ software. "Print" test experiment was run 5 times.

\section{Results and Discussion}

For each material type, planktonic bacteria amounts corresponding to the initial supernatant and the four rinsing solutions were summed for assessing bacteria growth in the liquid surrounding material samples (Figure 3). The corresponding bacterial growth inhibition rates, that were calculated with HA material as a reference, are given in Table 1. The significantly $(P<0.001)$ smaller planktonic bacteria amounts measured for all materials that contained SNPs (in comparison with HA material) clearly indicated that the growth of bacteria in medium was affected by the presence of SNPs in the materials. Since, as previously demonstrated [28], SNPs do not release from the materials used in this study, this antibacterial effect must be attributed to silver ions $\left(\mathrm{Ag}^{+}\right)$that were released in the surrounding liquid. $\mathrm{Ag}^{+}$ions are formed by oxidation of SNPs after contact with the surrounding aqueous medium, either at the material-liquid interface for SNPs exposed at the polymer matrix surface or after water uptake by the polymer matrix as already reported by other authors [25, 31]. In the last case, the nanoporous morphology structure of $\mathrm{HA}$ enables $\mathrm{Ag}^{+}$to diffuse through and to be released from the polymer matrix [28]. Accordingly, the HA polymer covering layer does not 


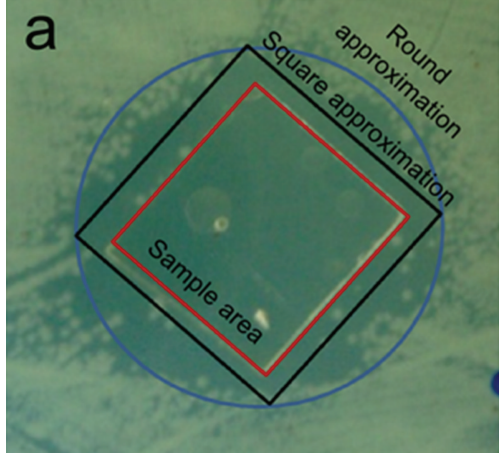

(a)

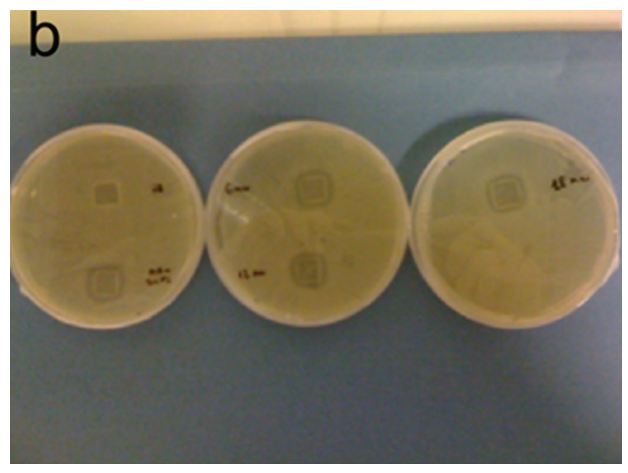

(b)



(c)

Figure 2: (a) Approximation of the inhibition area border by a round or square zone. (b) Example of the inhibition area observed around the HA film ("HA"), loaded with SNPs ("HA + SNPs"), and recovered by a second HA layer of $6 \mathrm{~nm}$ (“6 $\mathrm{nm}$ "), $12 \mathrm{~nm}$ (“12 nm"), and $18 \mathrm{~nm}$ ("18 nm") of thickness (2 different samples were placed on each plate). (c) Quantitative results of the diffusion test on LB agar plates for the 5 different types of material. $\S$ symbol indicates significant difference compared to HA $(P<0.01)$.

significantly affect the release of $\mathrm{Ag}^{+}$, which is in accordance with its suitability for $\mathrm{Ag}^{+}$diffusion. In addition, no significant difference in the quantity of planktonic bacteria was observed between the 4 SNPs-loaded materials. This further demonstrates that the second HA layer covering SNPs does not reduce the antibacterial activity on planktonic bacteria, that is, the antibacterial activity due to $\mathrm{Ag}^{+}$ions released in material surroundings. Finally, the antibacterial effect of SNPs-containing materials on planktonic bacteria can be attributed to inhibition of bacteria proliferation and death of

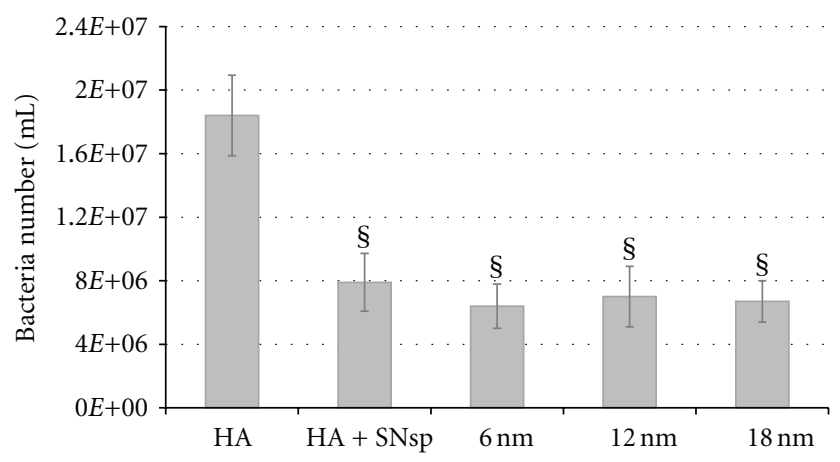

FIGURE 3: Amount of planktonic bacteria after 2 hours of culture in the surroundings of the following samples: HA film ("HA"), loaded with SNPs ("HA + SNPs"), and recovered by a second HA layer of $6 \mathrm{~nm}$ (“6 $\mathrm{nm}$ ”), $12 \mathrm{~nm}$ (“12 nm”), and $18 \mathrm{~nm}$ ("18 nm”) of thickness. Values were obtained by summing planktonic bacteria amount measured in the initial supernatants and the corresponding 4 rinsing solutions. $\S$ symbol indicates significant difference compared to HA $(P<0.001)$.

TABLE 1: Rates of bacteria growth inhibition, calculated with Negative Control as the reference.

\begin{tabular}{lccccc}
\hline $\begin{array}{l}\text { Material } \\
\text { sample type }\end{array}$ & $\begin{array}{c}\text { Negative } \\
\text { Control }\end{array}$ & $\begin{array}{c}\text { Positive } \\
\text { Control }\end{array}$ & $6 \mathrm{~nm}$ & $12 \mathrm{~nm}$ & $18 \mathrm{~nm}$ \\
\hline $\begin{array}{l}\text { Inhibition rate } \\
\text { Rtandard }\end{array}$ & Reference & $57 \%$ & $65 \%$ & $62 \%$ & $64 \%$ \\
\begin{tabular}{l} 
Deviation \\
\hline
\end{tabular} & & $5 \%$ & $5 \%$ & $8 \%$ & $4 \%$ \\
\hline
\end{tabular}

some bacteria. It is probable that, as proposed in the literature [19-21], both phenomena act together to disturb the growth of the planktonic population of bacteria.

Diffusion assays on nutritive agar plates confirmed the antibacterial effect resulting from loading of HA materials with SNPs. Images representative of the assays (Figure 2(b)) show the presence of bacterial growth inhibition zones (IZs) around the materials that were loaded with SNPs and the absence of this area for the SNPs-free HA polymer sample. This confirms that HA film does not release a substance able to inhibit $E$. coli growth which states that antibacterial effect revealed by all SNPs-containing materials is related to the presence of SNPs. In addition, IZ areas measurements (Figure 2(c)) show that HA + SNPs material led to an insignificantly wider IZ than SNPs-containing materials covered with a second HA layer. This highlights that the antibacterial effect due to $\mathrm{Ag}^{+}$released from embedded SNPs is possible even in the presence of an HA covering layer potentially as thick as $18 \mathrm{~nm}$. Nevertheless, $\mathrm{Ag}^{+}$diffusion through the second HA layer may slightly slow $\mathrm{Ag}^{+}$release in the aqueous medium surrounding materials.

Contrary to the antibacterial effect that was demonstrated for bacteria present in the surroundings of materials, the effect on bacteria adhered on the material surface was significantly dependent on the thickness of the covering HA layer. Through CLSM observation of adhered bacteria and subsequent micrograph analysis with ImageJ software, the number 


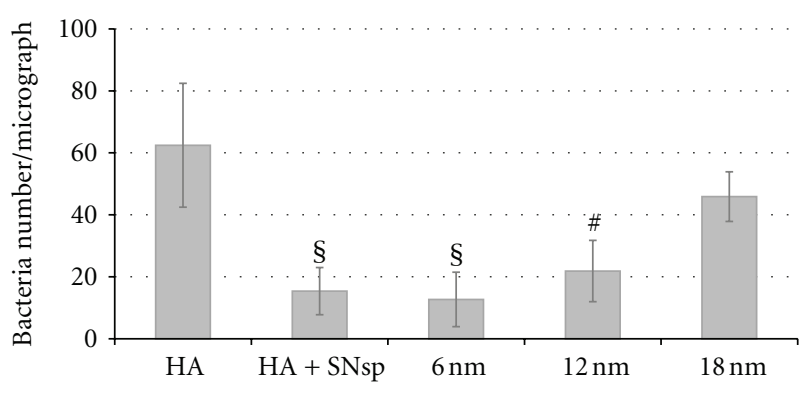

Figure 4: Number of E. coli adhered after $2 \mathrm{~h}$ of growth on HA film ("HA"), loaded with SNPs ("HA + SNPs"), and recovered by a second HA layer of $6 \mathrm{~nm}$ (“6 $6 \mathrm{~nm}$ ”), $12 \mathrm{~nm}$ (“ $12 \mathrm{~nm}$ ”), and $18 \mathrm{~nm}$ (" $18 \mathrm{~nm}$ ") of thickness. Results were obtained by analysing CLSM micrographs with ImageJ software. $\S$ and \# symbols indicate significant difference compared to HA $(P<0.005$ and $P<0.05$ resp.).

of bacteria adhered on the top of the HA + SNPs material surface was shown, as expected, to be dramatically less $(P>$ 0.005 ) than on HA material (Figure 4). Compared to HA, the number of adhered bacteria was also reduced on SNPsloaded films with a second HA layer. Nevertheless, this reduction was less marked on $12 \mathrm{~nm}$ material samples $(P>0.05)$ than on $6 \mathrm{~nm}$ material samples $(P>0.005)$ and still decreased on $18 \mathrm{~nm}$ material samples (nonsignificant difference between $18 \mathrm{~nm}$ and HA material samples). These results demonstrate that SNPs-containing materials result in a reduction of bacterial colonisation compared to SNPs-free HA. Nevertheless, the additional HA layers used to cover SNPs seem to limit the reduction of the antibacterial efficiency on adhered bacteria: increasing the layer thickness results in decreasing the SNPs-related effect on adhered bacteria.

Since planktonic bacteria were shown not to be differently affected by $\mathrm{Ag}^{+}$according to the thickness of the second $\mathrm{HA}$ layer, differences in $\mathrm{Ag}^{+}$release in aqueous medium due to different thickness of second layer might be too low to result in significant differences in the antibacterial effect on adhered bacteria. Hence, antibacterial effect on adhered bacteria must be attributed to a direct contact between cells and the SNPs-containing material, maybe due to $\mathrm{Ag}^{+}$accumulated at the material surface before final release. Assuming that HA polymer is a more favourable substrate for bacteria to adhere than SNPs and since the second HA layer is a thin, noncontinuous film presenting pores opened on the subjacent SNPs deposit, increasing the HA layer thickness increases the quantity of favorable sites for bacterial adhesion. Consequently, it is preferable that the second HA layer is as thin as possible to maintain a significant protective effect of the material on bacterial colonisation.

Bacterial physiology was also affected by the presence of SNPs in the materials. As shown by the micrographs realised with CLSM (Figure 5), bacteria that adhered on SNPs-free HA material presented a typical bacillus shape while, on SNPs-containing materials, bacterial morphology was modified: cells were shorter in length and had rounded shape. This change of the morphology of E. coli suggested that bacteria were unable to grow and proliferate, which is supported by the absence of divided cells on the SNPs-loaded surfaces. Such nongrowing state, that is known as one of the most common strategies used by bacteria to resist against antibacterial agents [32], can be here attributed to the presence of SNPs. However, it is difficult to distinguish between the potential roles of free $\mathrm{Ag}^{+}, \mathrm{Ag}^{+}$accumulated at the material surface, or SNPs accessible at the material surface.

To further assess the capacity for proliferation of adhered bacteria, an original method was developed: through a socalled "print test," bacteria adhered on the diverse materials were transferred to agar nutritive medium and areas covered by the colonies formed by the transferred bacteria were measured as an indication of bacteria vitality. Surprisingly, areas covered by bacterial colonies decreased according to the $\mathrm{HA}>\mathrm{HA}+\mathrm{SNPs}>6 \mathrm{~nm}>12 \mathrm{~nm}>18 \mathrm{~nm}$ ranking, as shown in Figure 6. The result demonstrated above (Figure 4), that is, the increase of adhered bacteria amount with the thickness of the HA layer covering SNPs, rather led to expect a decrease of the covered area following the HA $>18 \mathrm{~nm}>12 \mathrm{~nm}>$ $6 \mathrm{~nm}>\mathrm{HA}+\mathrm{SNPs}$ ranking. In other words, the results of the present study showed that the thickest covering HA layer presents the highest amount of attached cells, yet the smallest amount of cultivable, harvested cells. The difference of cultivable bacteria harvested by printing with HA samples and $18 \mathrm{~nm}$ covered SNPs samples (that showed similar numbers of adhered bacteria) may be attributed to the loss of cultivability of the adhered bacteria due to the silver-related toxic surroundings [5]. However, the cause of the decrease in adhered bacteria cultivability with the increase of the second HA layer thickness despite an oppositely increase in bacteria amount adhered on the surface is not obvious. We propose two hypotheses for explaining this phenomenon.

(i) The characteristics of the silver species present at the SNPs-containing material surface may be changed by plasma treatment leading to modify antibacterial efficiency. Quantity of $\mathrm{Ag}^{+}$or SNPs, charge of SNPs, shape of SNPs, and so forth may be concerned. One possible scenario is that $\mathrm{Ag}^{+}$that may remain in the material in an unreduced state (despite the $\mathrm{NaBH}_{4}$ based reduction process) may be reduced by plasma, thus leading to create new SNPs during the time of deposition of the second HA layer. Without or with noncontinuous second $\mathrm{HA}$ layer, $\mathrm{Ag}^{+}$that remained unreduced in the material may be eliminated soon after the coating elaboration. On the contrary, SNPs that may have been reduced under plasma may accumulate in the second HA layer surface and create a reservoir for further, slower release of more $\mathrm{Ag}^{+}$ $[25,33]$ in the close surroundings of the second layer. Hence, the contact-related antibacterial effect may be enhanced. Therefore, surfaces covered with thicker HA layer may present bacteria with less viability and cultivability, yet in higher number as mentioned above. In this scenario, the use of $18 \mathrm{~nm}$ thick covering HA layer should be preferred for enhancing the contact-related antibacterial effect, while protecting 


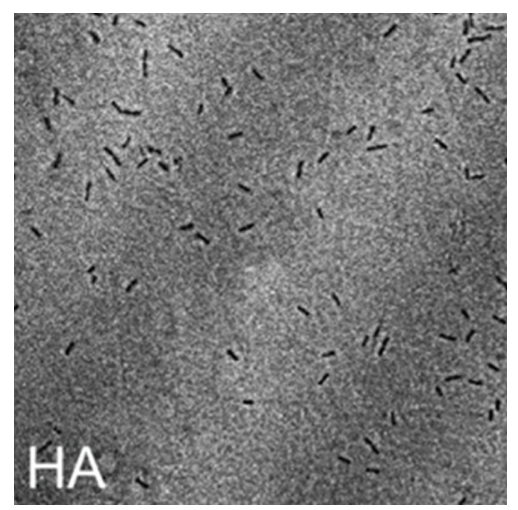

(a)

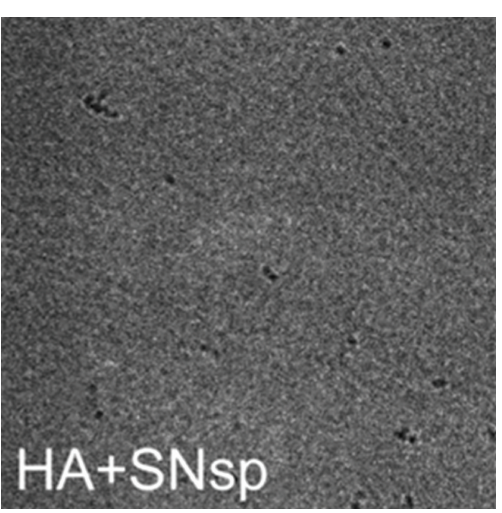

(b)

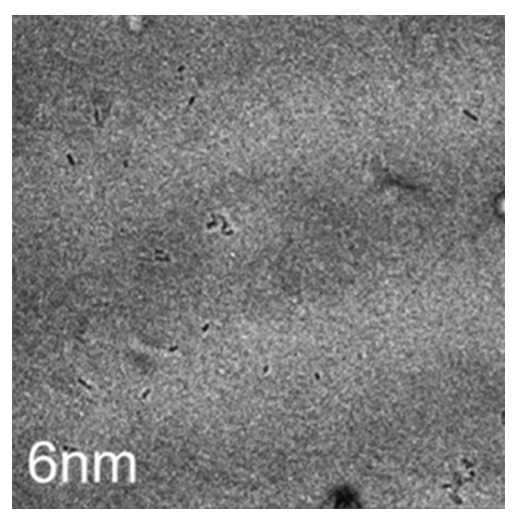

(c)

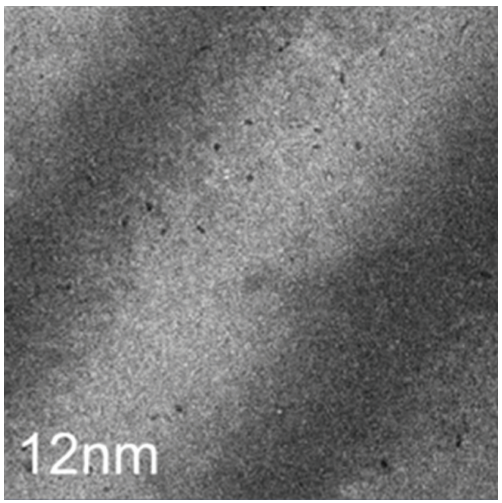

(d)

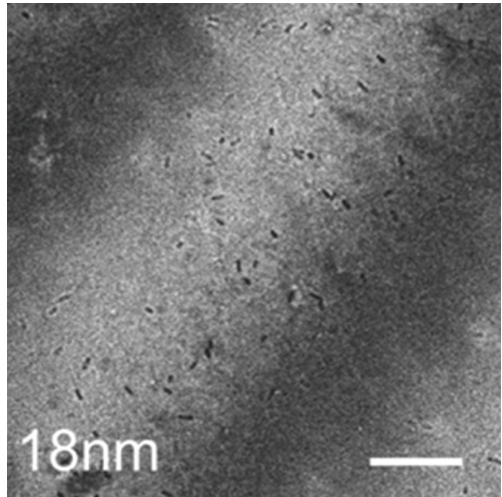

(e)

FIGURE 5: CSLM micrographs of E. coli adhered after $2 \mathrm{~h}$ of growth on HA film ("HA"), loaded with SNPs ("HA + SNPs"), and recovered by a second HA layer of $6 \mathrm{~nm}$ (“ $6 \mathrm{~nm}$ "), $12 \mathrm{~nm}$ (“12 nm”), and $18 \mathrm{~nm}$ (“18 nm") of thickness (Scale bar $20 \mu \mathrm{m}$ ).

eukaryotic cells from contact-related toxic effect of silver (as demonstrated elsewhere [28]).

(ii) Adhesion forces between bacteria and surface may be stronger on HA than on SNPs-containing material surfaces. Obviously, more bacteria should be harvested by printing when adhesion forces are smaller. Therefore, thicker, then larger covering with HA polymer of the SNPs deposit may result in larger retention of bacteria on the surface, leading to fewer bacteria that could be "printed" on the LB-agar plate. Comparing the ratio between the numbers of bacteria adhered on $18 \mathrm{~nm}$ material and HA + SNPs material $(3 \pm 2)$ and the ratio between the covered surfaces on $18 \mathrm{~nm}$ material (supposed to be recovered by a continuous layer of HA) and HA + SNPs material $(0.5 \pm$ 0.3 ), it is possible to estimate the ratio of bacterial adhesion strength between SNPs layer and HA layer at a value of $1 / 6$. If confirmed, this difference in adhesion strength may be a crucial indication for the elaboration of new antibacterial coatings based on the use of SNPs. In this scenario, the use of intermediate thickness of covering HA layer should be preferred for limiting the surface of HA polymer available for contact with bacteria, while preserving protective effect for eukaryotic cells.
Further investigations must be realized to distinguish between both effects, using fluorescence staining specific for bacterial bioactivity (viability and respiratory activity) to determine if bacteria metabolism is more affected on HA covered than on nude SNPs-containing materials. Additionally, force measurements (by AFM, e.g.) may allow to determine the bacterial adhesion strength ratio between HA and SNPs materials. Nevertheless, these unexpected results already allow to raise a new question about the antibacterial action of SNPs-containing materials and the methodology used to prove antibacterial efficiency. Whether the few quantity of agar transferred bacteria is due to low cultivability or high adhesion to HA material, antibacterial efficiency appears to be more complex as a simple action of $\mathrm{Ag}^{+}$released in the material surroundings. $\mathrm{Ag}^{+}$accumulation at the material surface and adhesion strength between bacteria and the SNPs-containing material surface may also play a crucial role in the success of an antibacterial material strategy.

\section{Conclusion}

We demonstrated here that SNPs-loaded material can be covered by thin HA polymer layer without losing the antibacterial activity on planktonic bacteria living in the near (liquid or semisolid) surroundings of the material. This activity was 

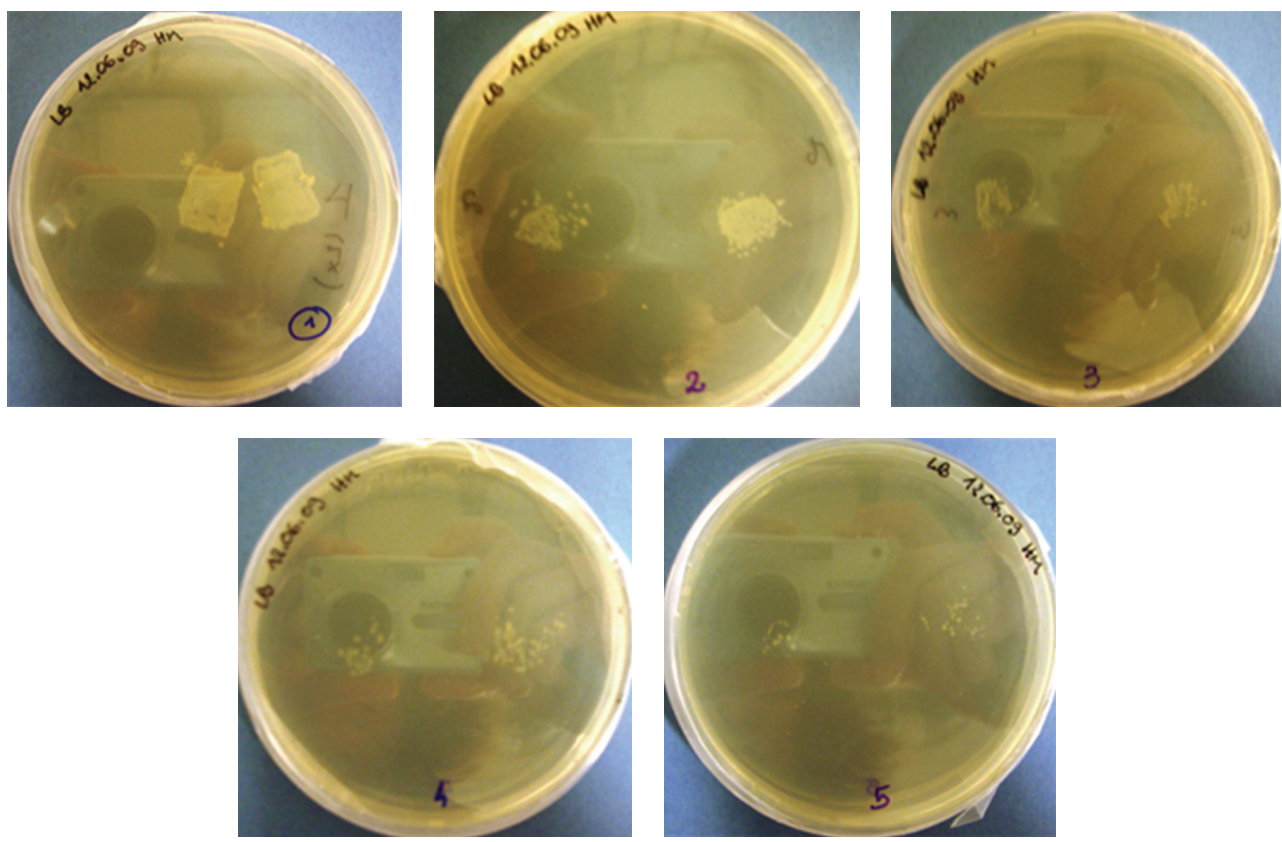

(a)

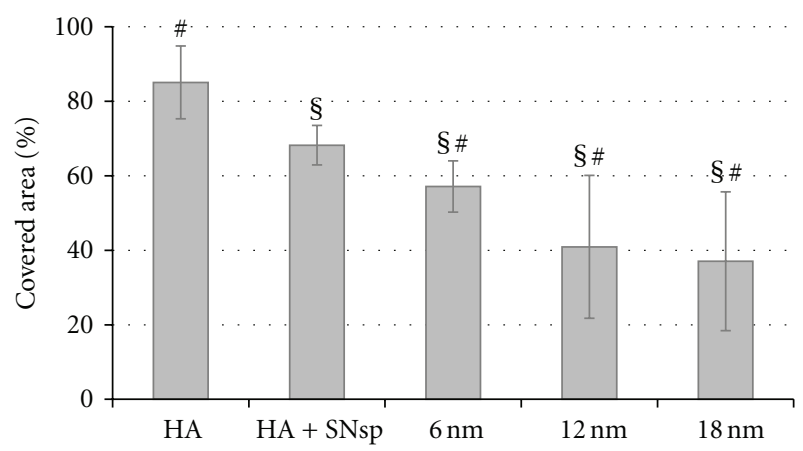

(b)

Figure 6: (a) Example of bacteria colonization after "print test" of the HA film ("HA"), loaded with SNPs ("HA + SNPs"), and recovered by a second HA layer of $6 \mathrm{~nm}$ (“6 $\mathrm{nm}$ "), $12 \mathrm{~nm}$ (“12 nm"), and $18 \mathrm{~nm}$ ("18 nm") of thickness (2 different samples were placed on each plate). (b) Rates of the print surfaces covered by bacteria colonies. Measurement was performed by image analysis using ImageJ software. $\S$ and \# symbols indicate significant difference compared to HA $(P<0.005)$ and HA + SNPs $(P<0.05)$ respectively.

maintained even with $18 \mathrm{~nm}$ thick HA layer covering SNPscontaining material. SNPs-containing materials also revealed an antibacterial effect on adhered bacteria. In general, adhered bacteria number was significantly less than on HA material and adhered bacteria physiology was affected on SNPs-containing HA materials. According to the thickness of the second HA layer, differences in adhered bacteria number were shown, indicating that antibacterial efficiency on adhered bacteria was not only due to indirect effect of released silver ions but was also the result of direct bacteria-surface contact. More precisely, the number of adhered bacteria decreased with the thickness of the second HA layer. Surprisingly, the quantity of cultivable bacteria harvested by transfer to nutritive agar decreased not only according to the presence of SNPs in the material coating, but also in relation with covering HA layer thickness, that is, oppositely to the increase in the number of adhered bacteria. We proposed two hypotheses to explain this surprising result. The first one suggests an enhancement of the SNPs-containing materials activity through plasma-induced modifications (increase of SNPs quantity, size or shape modification, e.g.). The second one suggests the existence of differences in the strength of bacterial adhesion to material surface depending on the fraction of the material surface covered by HA or SNPs. Bacteria observation under confocal microscope qualitatively demonstrated that the physiology of adhered bacteria was affected by the presence of SNPs, but failed to highlight any differences in physiology between SNPs-containing materials. These results raise the question of the diverse potential ways of action of SNPs entrapped in a polymer matrix, which we highlighted for the first time in this study. Further investigations are needed to conclude whether the small quantity 
of cultivable bacteria harvested by printing from HA-covered SNPs-containing materials is due to stronger attachment or to weaker vitality.

\section{Acknowledgments}

The authors thank the French Centre National de la Recherche Scientifique (CNRS) and Australian Research Council (ARC) (Fellowship FT100100292) for financial support.

\section{References}

[1] J. W. Costerton, P. S. Stewart, and E. P. Greenberg, "Bacterial biofilms: a common cause of persistent infections," Science, vol. 284, no. 5418, pp. 1318-1322, 1999.

[2] R. O. Darouiche, "Treatment of infections associated with surgical implants," The New England Journal of Medicine, vol. 350, no. 14, pp. 1422-1429, 2004.

[3] C. A. Fux, J. W. Costerton, P. S. Stewart, and P. Stoodley, "Survival strategies of infectious biofilms," Trends in Microbiology, vol. 13, no. 1, pp. 34-40, 2005.

[4] B. Gottenbos, H. J. Busscher, H. C. Van Der Mei, and P. Nieuwenhuis, "Pathogenesis and prevention of biomaterial centered infections," Journal of Materials Science, vol. 13, no. 8, pp. 717-722, 2002.

[5] J. Hardes, C. Von Eiff, A. Streitbuerger et al., "Reduction of periprosthetic infection with silver-coated megaprostheses in patients with bone sarcoma," Journal of Surgical Oncology, vol. 101, no. 5, pp. 389-395, 2010.

[6] L. Ploux, A. Ponche, and K. Anselme, "Bacteria/material interfaces: role of the material and cell wall properties," Journal of Adhesion Science and Technology, vol. 24, no. 13-14, pp. 21652201, 2010.

[7] K. Vasilev, J. Cook, and H. J. Griesser, "Antibacterial surfaces for biomedical devices," Expert Review of Medical Devices, vol. 6, no. 5, pp. 553-567, 2009.

[8] M. Zilberman and J. J. Elsner, "Antibiotic-eluting medical devices for various applications," Journal of Controlled Release, vol. 130, no. 3, pp. 202-215, 2008.

[9] R. M. Joyce-Wöhrmann and H. Münstedt, "Determination of the silver ion release from polyurethanes enriched with silver," Infections, vol. 27, supplement 1, pp. S46-S48, 1999.

[10] L. Rojo, J. M. Barcenilla, B. Vázquez, R. González, and J. San Román, "Intrinsically antibacterial materials based on polymeric derivatives of eugenol for biomedical applications," Biomacromolecules, vol. 9, no. 9, pp. 2530-2535, 2008.

[11] S. Simovic, D. Losic, and K. Vasilev, "Controlled drug release from porous materials by plasma polymer deposition," Chemical Communications, vol. 46, no. 8, pp. 1317-1319, 2010.

[12] H. J. Klasen, "A historical review of the use of silver in the treatment of burns. II. Renewed interest for silver," Burns, vol. 26, no. 2, pp. 131-138, 2000.

[13] J. M. Schierholz, L. J. Lucas, A. Rump, and G. Pulverer, "Efficacy of silver-coated medical devices," Journal of Hospital Infection, vol. 40, no. 4, pp. 257-262, 1998.

[14] A. Airoudj, E. Kulaga, V. Roucoules, and L. Ploux, "Mechanically switchable biocide plasma-polymer coatings for biomaterials," Advanced Engineering Materials, vol. 13, no. 10, pp. B360-B368, 2011.

[15] M. Ramstedt, B. Ekstrand-Hammarström, A. V. Shchukarev et al., "Bacterial and mammalian cell response to poly(3sulfopropyl methacrylate) brushes loaded with silver halide salts," Biomaterials, vol. 30, no. 8, pp. 1524-1531, 2009.
[16] A. Coughlan, D. Boyd, C. W. I. Douglas, and M. R. Towler, "Antibacterial coatings for medical devices based on glass polyalkenoate cement chemistry," Journal of Materials Science, vol. 19, no. 12, pp. 3555-3560, 2008.

[17] M. Malcher, D. Volodkin, B. Heurtault et al., "Embedded silver ions-containing liposomes in polyelectrolyte multilayers: cargos films for antibacterial agents," Langmuir, vol. 24, no. 18, pp. 10209-10215, 2008.

[18] K. Vasilev, V. R. Sah, R. V. Goreham, C. Ndi, R. D. Short, and H. J. Griesser, "Antibacterial surfaces by adsorptive binding of polyvinyl-sulphonate- stabilized silver nanoparticles," Nanotechnology, vol. 21, no. 21, Article ID 215102, 2010.

[19] Q. L. Feng, J. Wu, G. Q. Chen, F. Z. Cui, T. N. Kim, and J. O. Kim, "A mechanistic study of the antibacterial effect of silver ions on Escherichia coli and Staphylococcus aureus," Journal of Biomedical Material Research A, vol. 52, no. 4, pp. 662-668, 2000.

[20] W. K. Jung, H. C. Koo, K. W. Kim, S. Shin, S. H. Kim, and Y. H. Park, "Antibacterial activity and mechanism of action of the silver ion in Staphylococcus aureus and Escherichia coli," Applied and Environmental Microbiology, vol. 74, no. 7, pp. 2171-2178, 2008.

[21] I. Sondi and B. Salopek-Sondi, "Silver nanoparticles as antimicrobial agent: a case study on E. coli as a model for gramnegative bacteria," Journal of Colloid and Interface Science, vol. 275, no. 1, pp. 177-182, 2004.

[22] J. S. Kim, E. Kuk, K. N. Yu et al., "Antimicrobial effects of silver nanoparticles," Nanomedicine, vol. 3, no. 1, pp. 95-101, 2007.

[23] S. Pal, Y. K. Tak, and J. M. Song, "Does the antibacterial activity of silver nanoparticles depend on the shape of the nanoparticle? A study of the gram-negative bacterium Escherichia coli," Applied and Environmental Microbiology, vol. 73, no. 6, pp. 1712-1720, 2007.

[24] J. Hardes, H. Ahrens, C. Gebert et al., "Lack of toxicological side-effects in silver-coated megaprostheses in humans," Biomaterials, vol. 28, no. 18, pp. 2869-2875, 2007.

[25] R. Kumar and H. Münstedt, "Silver ion release from antimicrobial polyamide/silver composites," Biomaterials, vol. 26, no. 14, pp. 2081-2088, 2005.

[26] D. R. Monteiro, L. F. Gorup, A. S. Takamiya, A. C. RuvolloFilho, E. R. D. Camargo, and D. B. Barbosa, "The growing importance of materials that prevent microbial adhesion: antimicrobial effect of medical devices containing silver," International Journal of Antimicrobial Agents, vol. 34, no. 2, pp. 103-110, 2009.

[27] M. V .D. Z. Park, A. M. Neigh, J. P. Vermeulen et al., "The effect of particle size on the cytotoxicity, inflammation, developmental toxicity and genotoxicity of silver nanoparticles," Biomaterials, vol. 32, no. 36, pp. 9810-9817, 2011.

[28] K. Vasilev, V. Sah, K. Anselme et al., "Tunable antibacterial coatings that support mammalian cell growth," Nanoletters, vol. 10, no. 1, pp. 202-207, 2010.

[29] O. Vidal, R. Longin, C. Prigent-Combaret, C. Dorel, M. Hooreman, and P. Lejeune, "Isolation of an Escherichia coli K-12 mutant strain able to form biofilms on inert surfaces: involvement of a new ompR allele that increases curli expression," Journal of Bacteriology, vol. 180, no. 9, pp. 2442-2449, 1998.

[30] W. Rasband, ImageJ, U. S. National Institutes of Health, Bethesda, Md, USA, 1997.

[31] E. Körner, M. H. Aguirre, G. Fortunato, A. Ritter, J. Rühe, and D. Hegemann, "Formation and distribution of silver nanoparticles in a functional plasma polymer matrix and related $\mathrm{Ag}^{+}$release properties," Plasma Processes and Polymers, vol. 7, no. 7, pp. 619-625, 2010. 
[32] K. Lewis, "Riddle of biofilm resistance," Antimicrobial Agents and Chemotherapy, vol. 45, no. 4, pp. 999-1007, 2001.

[33] C. Damm, H. Münstedt, A. Rösch et al., "The antimicrobial efficacy of polyamide 6/silver-nano- and microcomposites," Materials Chemistry and Physics, vol. 108, no. 1, pp. 61-66, 2008. 

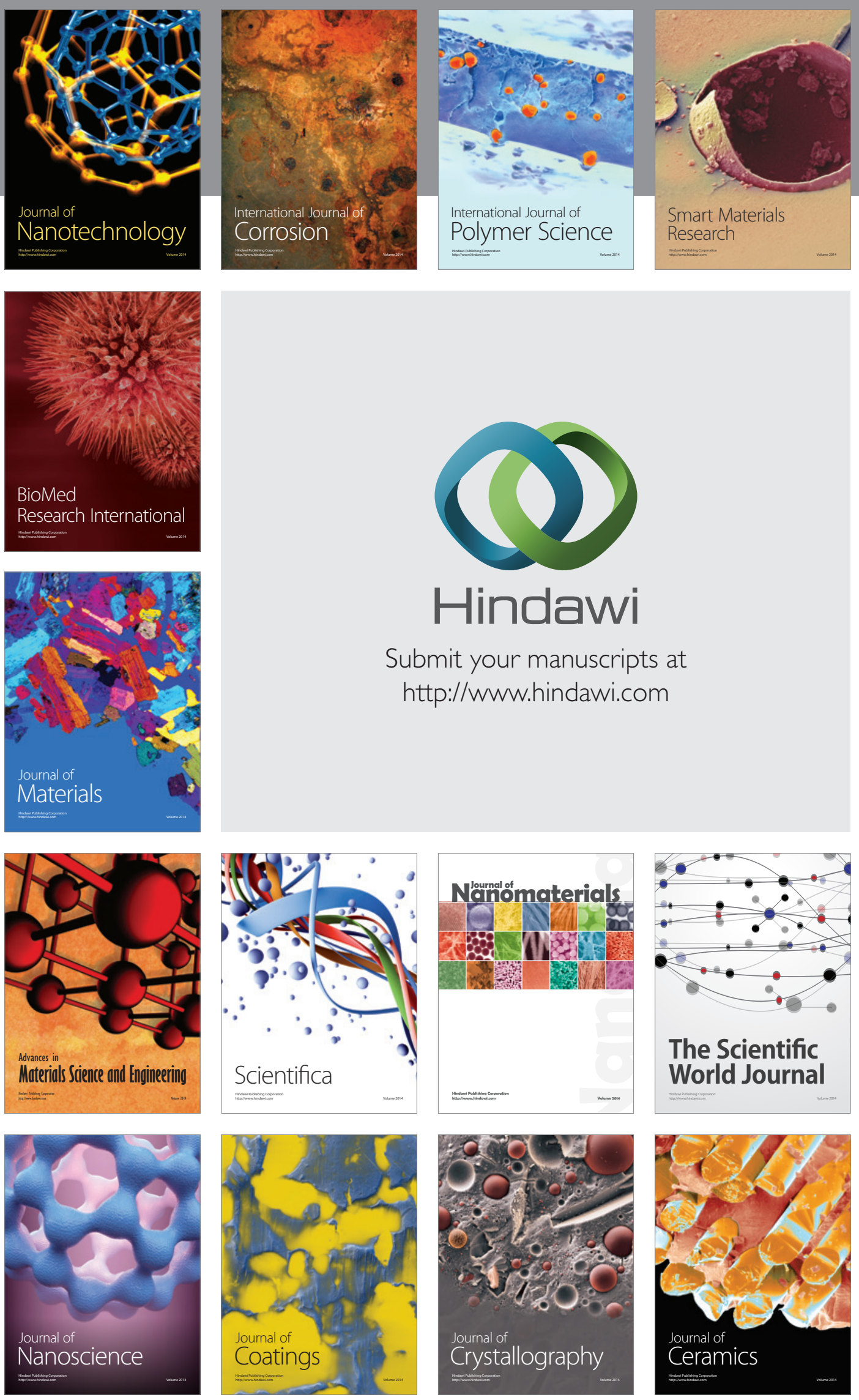

The Scientific World Journal

Submit your manuscripts at

http://www.hindawi.com

\section{World Journal}

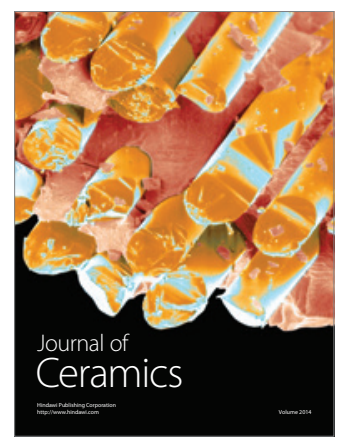

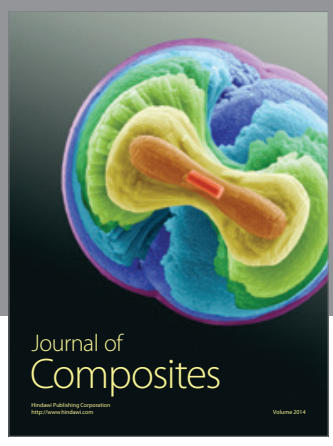
